training, suggesting that doctors learn best through applied 'leadership learning' as opposed to theory-driven programmes. Conclusions Drawing on Self-Determination Theory this study provides a theoretical framework for engaging doctors in Medical Leadership; assessing their leadership competency and learning needs and setting up reliable leadership training programmes. Doctors' ability to reliably determine their learning needs and the invaluable role of hands-on leadership/management experience in boosting doctors' leadership confidence, calls for more personalised and relevant learning plan that can build on their previous experience and expertise.

\section{WARNING BELL AGAINST THE RISE OF VIOLENCE WITH REGARD TO HEALTH PROFESSIONALS IN THE EMERGENCY DEPARTMENT}

M Lghabi*, W Allouche, B Benali, R Rhattas, A El Kholti. Casablanca Faculty of Medicine and Pharmacy, Hassan II University, Morocco

\subsection{6/oemed-2018-ICOHabstracts. 1060}

Introduction The violence is strongly present in the current hospital context, where the violence in the hospital is increasing, in particular with regard to harm to persons. The emergency department, as the hospital's multidisciplinary gateway, is now the most widespread hospital service with the highest number of acts of violence.

Methods This is a cross-sectional study conducted with the emergency department staff at a prefectural hospital in Casablanca using a self-administered questionnaire. The aim is to evaluate the violence in the emergency department and to define the methods of prevention.

Result Only 30 people (37.5\%) participated in the survey, with a female predominance $(66.6 \%)$. The average age was 35 years. $90 \%$ of our respondents feel exposed to violence in the performance of their duties. Nurses are the most exposed occupational category (34.6\%). Visitors and accompanying persons were the main perpetrators of the violence $(66.6 \%)$. Violence occurs more at night (39\%). 69\% of violence is harmful to people. Only $33.3 \%$ of the violence was reported to the administration.

Discussion Several studies, including ours, show a female predominance, this could be explained by the feminization of health personnel. In our study, visitors or accompanying persons were the most responsible for the violence $(66.6 \%)$, which is in line with several Moroccan studies. However, the 2014 annual report of the national observatory of violence in the health sector shows that in $72 \%$ of the perpetrators of the violence were patients. Personal injury is the most frequent, which is in accordance with the literature. On the other hand, the reporting rate remains relatively low compared to the literature.

Conclusion Violence against health personnel has become a daily reality. Its continuous rise has sounded the alarm calling to control this risk. Efforts should be pursued towards evaluation and prevention in order to optimise exercise safety.

\section{APPLYING PRACTICE GUIDELINES IN OCCUPATIONAL MEDICINE}

Tee Guidotti. Occupational + Environmental Health and Safety, Washington, DC, USA

10.1136/oemed-2018-ICOHabstracts.1061
Systematic critical appraisal and clinical epidemiology as represented by the Cochrane Collaboration have provided the methodology for the formulation of clinical 'practice guidelines' in many specialties and in primary care. Practice guidelines are valuable in establishing the standard of care, controlling costs, and improving consistency of outcomes. Critics charge that practice guidelines suppress innovation, constrain the practice of medicine, ignores differences in patient population, and are overly rigid given individual patient characteristics. The application of clinical guidelines to occupational medicine in the United States was pioneered by the American College of Occupational and Environmental Medicine (ACOEM), which developed and maintains the ACOEM Practice Guidelines (APG) using a Cochrane-like system of expert panels reviewing peer-reviewed evidence. The APG has become a widely accepted authoritative reference used especially workers' compensation systems to establish the standard of care. Problems include: Uneven evidentiary base (abundant and uninformative in the case of back pain, scanty and largely irrelevant for elbow and other issues); absence of clinical trials for occupationally-relevant outcomes; obstacles to performing outcomes studies and workplace intervention trials for injuries; characteristics of occupational disease such as latency, infrequency, and certainty of diagnosis; opposition by practitioners, mostly outside of occupational medicine; rigidity in application, not taking into account co-morbidity, patient characteristics, and complications; over-reliance on meta-analysis (which could be corrected by Bayesian analysis). Effectiveness of practice guidelines in occupational medicine has not been systematically studied except for cost, however. Performance assessment has been anecdotal. After having overseen the early APG program, the author's view was that practice guidelines for were a beneficial but partial solution, addressing different issues than in general medicine. The opinions expressed here are those of the authors and do not reflect a position of ACOEM.

\section{AVIATION MEDICINE: THE GLOBAL CHALLENGES TO REGULATORS AND AIRLINES}

Marcus GP Wong*. Durham University, Durham, UK

\subsection{6/oemed-2018-ICOHabstracts. 1062}

Aim of special session An overview about contemporary global challenges to aviation regulators and airlines

${ }^{1}$ Dr Tom Gaffney, ${ }^{2}$ Dr Elizabeth Wilkinson

${ }^{1}$ Irish Aviation Authority, Dublin, Republic of Ireland

${ }^{2}$ British Airways Health Services, Harmondsworth, UK

Regulatory aviation medicine/aeromedicine, a subsection of occupational medicine, aims to determine whether pilots are medically fit to fly either routinely or in response to a decrease in medical fitness. Traditionally, change occurs very slowly in aviation medicine, new treatments and technologies must be evidence based and well established before the standards will change. The role of the aviation medical regulator ('medical assessor') has become more demanding in the past 20 years as many complex ongoing clinical conditions have now been deemed compatible with safe flight. Therefore, many pilots are now deemed fit to fly where formerly their careers would have ended. In addition, regulators (competent authorities) around the world determine the medical standard 
for their own jurisdictions and standards differ both within and between jurisdictions. Formerly in Europe, aeromedical standards were more prescriptive, now they are more risk based and open to interpretation. Pilots frequently change competent authority and jurisdiction; this presents a challenge to medical assessors. Due to recent adverse events, more aspects of pilot medical assessments are becoming mandatory including formal psychological assessment, drug and alcohol testing and peer support for both pilots and aeromedical examiners. There is also a drive to include health promotion and preventative medicine as an integral part of routine medical examinations for pilots. This has been strikingly absent to date as the routine medicals focus on a 'pass/fail' system. As with any change in aeromedicine, a way that is acceptable to all involved is being established currently. Regulatory aeromedicine is truly international largely due to the 'client' base and the many medical services and regulators they encounter around the world in the course of their careers. For these very reasons, it is also an exciting field to work in.

In March 2015 another 'unthinkable' happened in aviation with the Germanwings disaster. The world was shocked as events unfurled, and for commercial aviation the tragic situation had to be risk assessed with speed. Individual airlines considered their own risk assessment and the European Aviation Safety Agency, EASA, set up a Task Force in May 2015, their report being published in July 2015. The Task Force made the following 6 recommendations:

1. The principle of 'two persons in the cockpit at all time' should be maintained.

2. Pilots should undergo a psychological evaluation before entering airline service.

3. Airlines should run a random drugs and alcohol programme.

4. Robust programme for oversight of aeromedical examiners should be established.

5. A European aeromedical data repository should be created.

6. Pilot support systems should be implemented within airlines.

The French accident investigation report (BEA) was also published with its own recommendations. Such detailed analysis of all aircraft accidents is required to help improve flight safety and recommendations often follow, some more controversial than others. This presentation will review some of the recommendations in detail discussing the implications, implementation, and benefits to flight safety.

\section{HYPERBARIC MEDICINE (DEALING WITH EMPLOYEES WHO WORK UNDER PHYSICAL PRESSURE)}

AJ Bray*. SWIMS Ltd, Solihull, UK

\subsection{6/oemed-2018-ICOHabstracts. 1063}

Aim of special session Using 3 related employment scenarios to explore the increasing challenges to employees working under pressure and their medical attendants.

Presenters: M. Gonevski ${ }^{1}$, W. Robertson ${ }^{2}$, A. Heili ${ }^{3}$

${ }^{1}$ Midlands Diving Chamber, Rugby, UK

${ }^{2}$ Independent Occupational Physician, Yorkshire, England

${ }^{3}$ Hyperbaric Tunnelling and Medical Services- Romford, UK Description of content The scope of the working community who toil under increased physical pressure will be collectively addressed in this interactive workshop. New equipment, techniques and operating protocol will be debated to focus the delegates on scientific evidence and recent accident data.

The individual topics are inter-related and cover the breadth of the working practices of tunnelling, diving and hyperbaric chamber activities. The speakers will cover tunnelling technology, medical criteria for chamber staff and the threatening use of bizarre and dangerous diving breathing systems.

Following a brief historical analysis the individual presenters with provide updating material to set the scene and aid participation in constructive dialogue.

\section{0a QUALIFICATION AND REQUIREMENTS FOR HYPERBARIC CHAMBER FACILITY PERSONNEL}

M Gonevski. Midlands Diving Chamber, Rugby, UK

\subsection{6/oemed-2018-ICOHabstracts. 1064}

The range of personnel involved in hyperbaric chamber operations requires a specific set of skills. There are minimum requirements for all key level positions with regards to training, experience and medical fitness and these are discussed in detail. The appropriate staff numbers and their qualifications depend on the combination of patient numbers and needs, chamber type and features, as well as the use of medical and other equipment. For a standard multi-place chamber the minimum complement must comprise of a hyperbaric physician on-site, a minimum of one qualified attendant available inside and one outside the chamber, as well as a hyperbaric technical officer. Depending on the type of patients being treated, there may be a necessity for an intensive care trained nurse as hyperbaric attendant. The qualifications and responsibilities can overlap between the hyperbaric facility personnel. The training requirements are also very specific. The Hyperbaric Physician must have knowledge, training and experience in the diagnosis, treatment and assessment of individuals in whom hyperbaric oxygen therapy is contemplated. He is medically accountable for the safety of patients and staff involved in the treatment. This requires knowledge of the indications, contraindications, side effects and complications of therapy, as well as provisions of an environment to safely treat patients. The Hyperbaric Attendant must be a nurse or a diving medical technician with emergency medical training. They must possess both theoretical and practical knowledge and competencies. This is achieved through successful completion of a training course that covers specific relevant curriculum. Before any medical personnel can enter hyperbaric environment they must be certified as medically fit to undergo pressurisation. The person's fitness is determined through a medical examination that comprises of a detailed medical questionnaire and a medical examination conducted by a medical practitioner appropriately trained in hyperbaric and diving medicine.

\section{0b HOOKA DIVING SYSTEMS}

W Robertson. Independent Occupational Physician, Yorkshire, UK

10.1136/oemed-2018-ICOHabstracts. 1065

Diving is an incredibly common activity both in the recreational and commercial domain. Despite being an activity 